\title{
OPTIMIZATION OF THE ELECTRICAL NETWORK BY THE ANT COLONY METHOD
}

\author{
Sihem BOURI, Abdelhalim BENMANSOUR \\ Materials and Renewable Energy Research Unit (URMER), \\ University Aboubekr Belkaid Tlemcen BP 119 - 13000, Algeria, \\ E-mail: bouri_sihem@yahoo.fr, halim.benmansour13@gmail.com
}

\begin{abstract}
A system is a set of processes and equipment to perform a task or a mission. The rational exploitation of the system depends on its configuration. An optimal configuration avoids excessive expenses. The primary function of a modern electric power system is to provide its customers with electrical energy as economically as possible with an acceptable degree of reliability. This degree of hope requires an optimal design. In the engineering context, choosing equipment based on availability, cost, and performance is the most important decision variable for optimizing a process. Depending on the availability of technologies on the market, the development of an iterative algorithm will be necessary in order to adapt to each request its optimal structure. This article discusses the resolution of a set of coherent problems that must be maximized, minimized, or minimized-to maximize single-objective or multi-objective functions under a set of constraints. These types of problems are called Max-Min / or Min-Max functions.
\end{abstract}

Keywords: Optimization, Meta-heuristics, Ant algorithm, Reliability, Multi-state system, product system

\section{INTRODUCTION}

The design of a power generation, transmission and distribution system must consider, first and foremost, continuity of service. For this, when designing our system, we must focus on finding the optimal configuration that ensures the feasibility, efficiency, robustness and rational operation of the system to be designed. This without forgetting to think about the cost. For this purpose, the designer must estimate the cost of equipment and especially the management of defects and time and cost of operation. Optimizing the design of a system aims to find the configuration that offers the best compromise.

The types of solutions available to meet energy supply needs are many and varied. We can mention: the installation of new generation equipment in the network in question, the installation of new transmission lines to access the production equipment of neighboring networks, etc. This is to intervene in real time in case of default, reduce operating costs and ensure continuity of service.

One of the meta-heuristics that has revolutionized research in this field is the ACF: these are the ACF ant (ant colony algorithm) algorithms. This heuristic has been applied to many systems, [1] [2] [3] [4] [5] [6] [7] [8] [9] [10], and has proved advantageous in terms of robustness and efficiency. It remains to model the production of energy using this heuristic and test its reliability.

The goal of our work is to optimize the design of an electrical network by using objective functions for optimal choice of components according to the ant colony method in order to design a new concept of continuous supply of electrical energy at lower cost.

The objective functions considered are twofold: Minimize the cost of the system under the minimum reliability constraint and Optimize the reliability of the system under the constraint of the costs of design, implementation and operation of the system. The test must therefore consider both minimizing costs and maximizing reliability under the constraints of reliability and cost.

\section{SUBJECT}

The problem to solve is to optimize an objective cost function under reliability constraints. In other words, it is a question of selecting the best combination of elements in order to minimize the total cost while respecting the required level of reliability.

Items can be selected in any combination of items available on the market and any order.

In order to apply ACO to the problem of optimizing systems in parallel series, the problem is represented by a graph $G=(V, E)$ whose vertices correspond to the subsystems and to the available elements and whose edges represent the paths connecting the subsystems to their corresponding elements. On each side is also associated a weight according to the quality of the equipment (reliability, performance and cost) chosen.

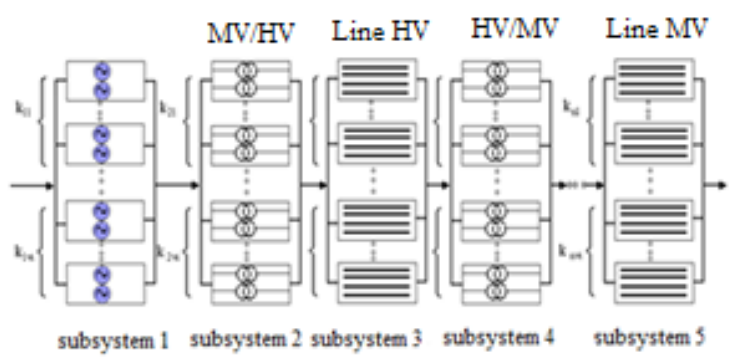

Fig. 1 Power- energetic parallel-series system

The ants are guided, during the construction of a system, by the heuristic information specific to the problem which is inversely proportional to the cost of the elements (the ants choose the least expensive elements) and to the pheromone rate (experiment of other ants).

Consider a parallel series system containing $n$ subsystem $\mathrm{C}_{\mathrm{i}}(\mathrm{i}=1,2, \ldots, \mathrm{N})$ in a series arrangement as shown in Fig. 1. 
Each subsystem $\mathrm{Ci}$ contains a number of elements or components connected in parallel. For each subsystem i, there is a different version of the elements (generators, transformers and lines) available on the market. For each subsystem of elements, different versions and number of components can be chosen. For each subsystem i, the elements are characterized by their costs $\left(\mathrm{C}_{\mathrm{iv}}\right)$, their reliability $\left(R_{\mathrm{iv}}\right)$ and their performances $\left(G_{i v}\right)$ attributed to their versions. The structure of the element system i can be defined by the number of elements or components in parallel (of each version) $\mathrm{k}_{\mathrm{iv}}$, where $\mathrm{V}_{\mathrm{i}}$ is the number of versions of elements of type $i$. The structure of the whole system is defined by vectors. For a set of vectors $\mathrm{k}_{1}, \mathrm{k}_{2}, \ldots$, $\mathrm{K}_{\mathrm{n}}$, the total cost of the system is given by the following expression:

$$
C=\sum_{i=1}^{n} \sum_{\nu=1}^{V_{i}} k_{i v} C_{i v}
$$

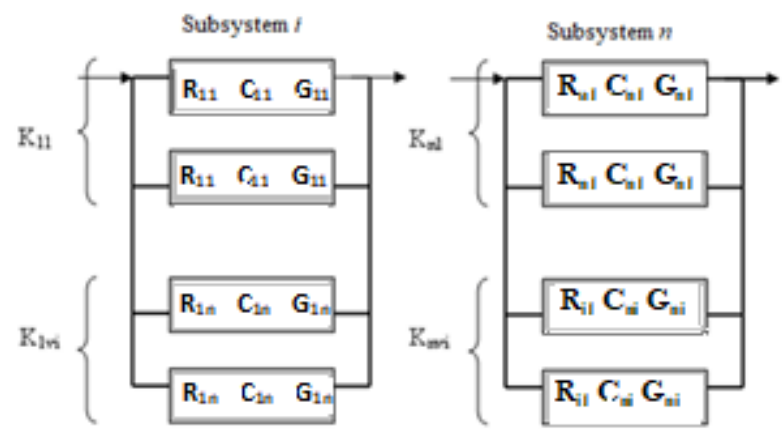

Fig. 2 Detailed diagram of a parallel-series system

\section{Primal problem}

The problem of optimizing a redundant multi-state system can be formulated as follows: find the configuration where the minimum cost system structure $\mathrm{k}_{1}, \mathrm{k}_{2}, \ldots, \mathrm{k}_{\mathrm{n}}$ which is at a higher or equal reliability level to that indicated threshold $\mathrm{R}_{0}$.

Minimise

$$
C=\sum_{i=1}^{n} \sum_{v=1}^{V_{i}} k_{i v} C_{i v}
$$

Under Constraint

$$
\begin{aligned}
& \prod_{i=\mathbf{1}}^{n}\left[\prod_{j=\mathbf{1}}^{J_{i}} p, q(Z) \min _{i=1}^{n} \sum_{j=1}^{J} G_{i j}\right] \geq R_{\mathbf{0}} \\
& \eta_{i j}=\mathbf{1} /\left(\mathbf{1}+c_{i j}\right)
\end{aligned}
$$

$c_{i j}:$ Represents the cost associated with the subsystem machine.

\section{Dual problem}

The optimization problem of a redundant multi-state system can be formulated as follows: to maximize $\mathrm{R}$ of a structure $\left(\mathrm{k}_{1}, \mathrm{k}_{2}, \ldots, \mathrm{k}_{\mathrm{n}}\right)$ whose cost is less than or equal to a certain given budget.

\section{Maximise}

$$
\operatorname{Max}\left[(R(t))=\prod_{i=1}^{n}\left[\prod_{j=1}^{J_{i}} p, q(Z) \min _{i=1}^{n} \sum_{j=1}^{J} G_{i j}\right]\right]
$$

Under Constraint

$$
\begin{aligned}
& C=\sum_{i=1}^{n} \sum_{v=1}^{V_{i}} k_{i v} C_{i v} \leq C_{\mathbf{0}} \\
& \boldsymbol{\eta}_{i j}=F
\end{aligned}
$$

\section{Trial problem (Multi-Objective)}

This problem includes a bi-objective function to optimize for a redundant multi-state system that can be formulated as follows:

Find the configuration / where the system structure $\mathrm{k}_{1}, \mathrm{k}_{2}$, $\ldots, \mathrm{k}_{\mathrm{n}}$ is cheaper, but its reliability is maximum with a set of constraints.

These problems usually take the name of multi-objective optimization. This optimization method allows flexible use according to the needs of the designer.

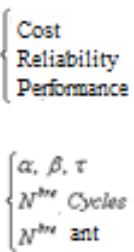

$N^{* n}$ ant

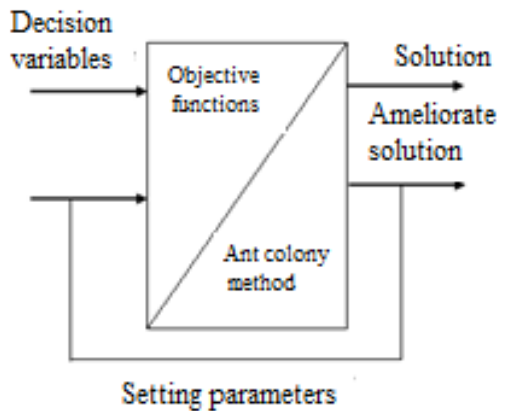

Fig. 3 Structure of multi-objective optimization
Min- Max

$\operatorname{Min}\left[C=\sum_{i=1}^{n} \sum_{v=1}^{V_{i}} k_{i v} C_{i v}\right]$

$\operatorname{Max}\left[(R(t))=\prod_{i=\mathbf{1}}^{n}\left[\prod_{j=\mathbf{1}}^{J_{i}} p, q(Z) \min _{i=1}^{n} \sum_{j=1}^{J} G_{i j}\right]\right]$

Under Constraint

$$
\begin{aligned}
& \prod_{i=\mathbf{1}}^{n}\left[\prod_{j=\mathbf{1}}^{J_{i}} p, q(Z) \min _{i=\mathbf{1}}^{n} \sum_{j=1}^{J} G_{i j}\right] \geq R_{\mathbf{0}} \\
& C=\sum_{i=1}^{n} \sum_{v=1}^{V_{i}} k_{i v} C_{i v} \leq C_{0}
\end{aligned}
$$




$$
\boldsymbol{\eta}_{i j}=F /\left(\mathbf{1}+c_{i j}\right)
$$

\section{METHODS}

\subsection{Presentation of the electrical network}

The adaptation of the electricity grid to its load is done by analogy to a serial parallel industrial process such as agribusiness. Often an electrical network (generation, transport, distribution and distribution) is presented as a configuration containing several columns with parallel components in series (subsystems) coupled to a model of load as shown in the following figure:

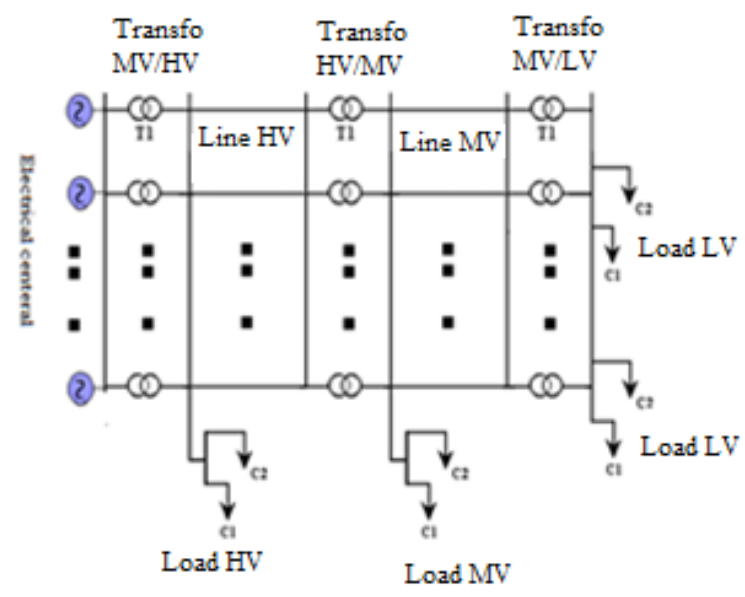

Fig. 4 Parallel series structure of an electrical network

Production subsystem (Generator): It is the main vertebra of the global electrical network system, it is the subsystem No. 1 of all parallel-serial subsystems. Electrical energy is well born from this cradle formed by a set of generators productions, they can be presented by their nature or version (type-provider), by their costs and their performance (active or apparent power). note by $\mathrm{Gi}$ the individual performance and $\mathrm{Ci}$ the costs of each generator forming the subsystem. The final product of this subsystem is Kwh. The latter is transited to another subsystem where it must be transformed and evacuated.

Transformation Subsystem (Transformer MV/HV): Generally, the subsystem generators operate at a voltage between 3-20 Kv, so transporting this energy requires $\mathrm{MV} / \mathrm{HV}$ transformation. These transformers operating in parallel are assumed to have zero losses. This Subsystem encompasses a heterogeneous set of transformers (different performance, version, and cost).

Transport subsystem (Line HV): Makes the basis of a tree configuration whose voltage level is the same. Then these lines are placed in parallel and try to pass the energy from the upstream point to the downstream point.

Transformation subsystem (Transformer HV/MV): This subsystem consists of a set of parallel transformers whose capacity or total performance is the sum of the performances of the different versions and types of transformers, the characteristic that changes is the level of $\mathrm{HV} / \mathrm{MV}$ voltage.
Transport subsystem (Line MV): The transport subsystem is usually based on medium voltage lines that supply medium voltage customers. The configurations are always arborescent. These lines are placed in parallel.

The transport subsystem is coordinated with HV line, HV / MV transformer and MV line (Fig. 5)

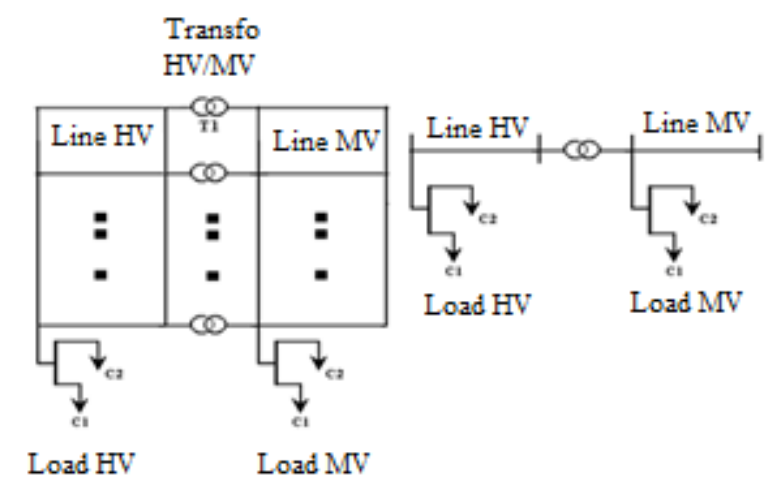

Fig. 5 Subsystem transport

\subsection{The ACO principle}

Recently, (Dorigo, Maniezzo and Colorni, 1996) introduced a new approach to optimization problems derived from the study of any colonies, called "Ant System". Their system inspired by the work of real ant colonies that exhibit the highly structured behaviour [14] [15]. Ants lay down in some quantity an aromatic substance, known as pheromone, in their way to food. An ant chooses a specific path in correlation with the intensity of the pheromone. The pheromone trail evaporates over time if no more pheromone in laid down by others ants, therefore the best paths has more intensive pheromone and higher probability to be chosen. This simple behaviour explains why ants are able to adjust to changes in the environment, such as new obstacles interrupting the currently shortest path.

Artificial ants used in ant system are agents with very simple basic capabilities mimic the behaviour of real ants to some extent. This approach provides algorithms called ant algorithms [16]. The Ant System approach associates pheromone trails to features of the solutions of a combinatorial problem, which can be seen as a kind of adaptive memory of the previous solutions. Solutions are iteratively constructed in a randomized heuristic fashion biased by the pheromone trails [13], left by the previous ants. The pheromone trails, $\tau_{i j}$, are updated after the construction of a solution, enforcing that the best features will have a more intensive pheromone. An Ant algorithm presents the following characteristics. It is a natural algorithm since it is based on the behaviour of ants in establishing paths from their colony to feeding sources and back. It is parallel and distributed since it concerns a population of agents moving simultaneously, independently and without supervisor. It is cooperative since each agent chooses a path on the basis of the information, pheromone trails, laid by the other agents with have previously selected the same path. It is versatile that can be applied to similar versions the same problem. It is robust that it can be applied with minimal changes to other combinatorial optimization problems. The solution of the 
travelling salesman problem (TSP) was one of the first applications of ACO.

Various extensions to the basic TSP algorithm were proposed, notably by Dorigo and Gambardella (Dorigo and Gambardella, 1997a) [11], [12], [16], [17] et [18]. The improvements include three main aspects: the state transition rule provides a direct way to balance between exploration of new edges and exploitation of a priori and accumulated knowledge about the problem, the global updating rule is applied only to edges which belong to the best ant tour and while ants construct solution, a local pheromone updating rule is applied. These extensions have been included in the algorithm proposed in this paper.

\subsection{Equations}

$\mathrm{m}$ ants are initially positioned on a vertex representing a subsystem. Each ant will represent a possible configuration of the system. This configuration consists of $\mathrm{n}$ subsystems in series, each subsystem $\mathrm{i}$ in turn consists of $\mathrm{k}_{\mathrm{i}}$ elements in parallel. The $\mathrm{k}_{\mathrm{i}}$ elements of each subsystem are selected from any combination of the available elements. Each ant builds a solution, an ant placed on subsystem $\mathrm{i}$ chooses a machine $\mathrm{j}$ by applying a state transition rule given by:

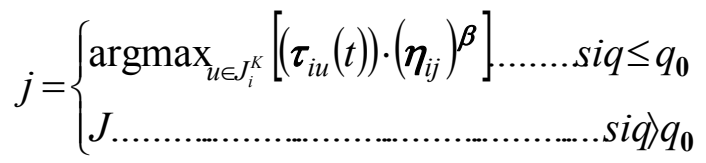

$$
P_{i}^{K} J(t)=\frac{\left(\tau_{i} J(t)\right) \cdot\left(\eta_{i} J\right)^{\beta}}{\sum_{l \in J_{i}^{K}}\left(\tau_{i l}(t)\right) \cdot\left(\eta_{i l}\right)^{\beta}}
$$

where:

$\alpha$ : Represents the relative importance of the pheromone trail.

$\beta$ : Represents the relative importance of the heuristic information $\eta_{i j}$.

$A C_{i}$ : Represents all the elements available for subsystem $\mathrm{i}$.

\section{$q_{0}:$ Random number between 0 and 1.}

The parameter determines the relative importance of exploitation against exploration: whenever an ant on a subsystem $\mathrm{i}$ must choose a machine $\mathrm{j}$, it first generates a random number if, therefore, the best edge is selected following the relation (12) (exploitation), otherwise an edge is chosen according to the relation (13) (biased exploration).

The update of the pheromone consists of two phases:

Local update.

Global update.
During the construction of a solution, the ant modifies the amount of pheromone on the edges visited by the application of the rules of update. The local update is introduced to avoid premature convergence and reduces the amount of pheromone on the edge connecting a given machine to its subsystem so as to discourage the next ant from choosing the same machine during the same cycle. The local update is given by:

$$
\tau_{i j}{ }^{\text {new }}=(\mathbf{1}-\boldsymbol{\rho}) \tau_{i j}{ }^{\text {old }}+\rho \Delta \tau_{i j}
$$

$\rho$ : is a coefficient so $(1-\rho)$ that represents the evaporation of the pheromone trace and $\tau_{\mathbf{0}}$ an initial value of the intensity of the pheromone trace.

Once all the ants have chosen their structure during a cycle, the amount of pheromone on the edges belonging to the best solution of the cycle (better ant) is reinforced again by applying the rule of global update

$$
\tau_{i j}{ }^{n e w} \rightarrow(\mathbf{1}-\boldsymbol{\rho}) \boldsymbol{\tau}_{i j}{ }^{\text {old }}+\boldsymbol{\rho} \tau_{\mathbf{0}}
$$

The final solution is the best solution found during all cycles and it is obviously the one that satisfies the constraint of reliability at lower cost.

A program (ANT OPTI) has been designed for optimizing the structures of parallel multistate series systems [19].

\subsection{Description of the algorithm}

Case of a fluid production structure (eg electro-energy industry (production, transport and distribution of electrical energy), plastic recycling industry, electronic chain industry, etc.).

Step 1:

Set NC: $=0 \quad / *\{$ NC: Conteur de Cycle $\} *$

For each arc $(i, j)$ put an initial value

$$
\tau_{\mathrm{ij}}(0)=\tau_{\mathrm{o}} / *\{\text { initial pheromone level }\}^{*} / \text {. }
$$

Step 2:

For $\mathrm{k}=1$ to $\mathrm{Nb}\{$ ants $\}$ do $/ *\{\mathrm{Nb}$ number of ants on the subsystem $\} * /$.

For $\mathrm{j}=1$ to Mmax Composants do $/ *\{(\operatorname{Mmax}$ : Components or elements the technical maximum on a subsystem (generator, transformers, or transport lines) $\} * /$.

Choose a component or elements, introduce an empty component $\{$ blanks\}, respecting the probability equations (1) and (2). 
Make a Local Update of the pheromone track to choose a component of the subsystem arc $(i, j)$ :

$$
\tau_{i j}^{n e w} \rightarrow(1-\rho) \tau_{i j}^{o l d}+\rho \tau_{o}
$$

End For

Step 3:

Calculate $\mathrm{Ak}$ or $\mathrm{Rk} / *$ \{System reliability for each ant $\} * /$.

\{Ushakov method\}:

For $\mathrm{j}=1$ to $\mathrm{kmax} / *\{\operatorname{kmax}\}: / *$ Maximum number of components or elements in parallel $* /$.

\{Applying the equations\}:

$$
\left\{\begin{array}{l}
u_{p}(z)=\prod_{j=1}^{J_{m}} u_{j}(z) \\
u_{j}(z)=\sum_{i=1}^{n} P_{i} z^{a_{i}}
\end{array}\right.
$$

For $\mathrm{i}=1$ to $\mathrm{n} / * \mathrm{n}$ : number of subsystems in series $* /$.

\{Applying the equations\}:

$$
\begin{gathered}
u_{s}(z)=\boldsymbol{\delta}\left(u_{\mathbf{1}}(z), \quad u_{\mathbf{2}}(z), \ldots, u_{m}(z)\right) \\
\boldsymbol{\eta}\left(u_{\mathbf{1}}(z), \quad u_{\mathbf{2}}(z)\right)=\boldsymbol{\delta}\left(\sum_{i=1}^{n} P_{i} z^{a_{i}}, \sum_{j=1}^{m} Q_{j} z^{b_{j}}\right) \\
=\sum_{i=1}^{n} \sum_{j=1}^{m} P_{i} Q_{j} z^{\min \left\{a_{i}, b_{j}\right\}}
\end{gathered}
$$

Calculate the total cost $/ *$ Cost of the structure or topology of each ants $* /$.

\{Applying the equation\}:

$$
C=\sum_{i=1}^{n} \sum_{v=1}^{V_{i}} k_{i v} C_{i v}
$$

Make a global update and save the best solution

/ $*$ Structure of the best ant $* /$.

Step 4:

Global Update for the Pheromone Track / * Structure of the Best Ant*/
For each arc $(i, j) \in$ to the best solutions, Update the pheromone track

\{Applying the equations\}:

$$
\tau_{i j}^{\text {new }} \rightarrow(\mathbf{1}-\rho) \tau_{i j}^{\text {old }}+\rho \Delta \tau_{i j}
$$

$$
\Delta \tau_{i j}=\left\{\begin{array}{lr}
\frac{1}{T C_{b e s t}} & \text { if }(i, j) \in \text { best } \\
\mathbf{0} & \text { otherwise }
\end{array}\right.
$$

End For

Step 5:

Cycle $=$ Cycle +1

If $\{\mathrm{NC}<\mathrm{N} \mathrm{Cmax}\}$ and / * behavior without stagnation \{behavior without stagnation /*

$$
\begin{aligned}
& \text { Then } \\
& \text { Goto step } 2
\end{aligned}
$$

Else

Print and save the best solution / * structure with the best component $* /$.

Stop.

\section{RESULTS}

The structure of the grid network, involves the following columns (subsystems) to execute all the phases concerning the production transformation distribution and distribution of energy. These columns are illustrated below:

Gi: Represents performance or capacity in $\%$ of power total.

Pi: Represents the reliability of the element in $\%$.

Ci: Represents the cost in $\%$ of the investment on each column (subsystem).

1-Column $\{1\}$ represents the subsystem 1 (energy production) which comprises four (04) power generators of 4. $200 \mathrm{Mw}$.

\begin{tabular}{|c|c|c|c|c|}
\hline & $\mathbf{1}$ & $\mathbf{2}$ & $\mathbf{3}$ & $\mathbf{4}$ \\
\hline Gi \% & 100 & 98 & 95 & $\mathbf{1 2 0}$ \\
\hline Pi \% & 89.9 & 99.7 & 78 & $\mathbf{7 9 . 7}$ \\
\hline Ci \% & $\mathbf{4 5}$ & $\mathbf{1 1 5}$ & $\mathbf{2 . 5}$ & $\mathbf{1 5}$ \\
\hline
\end{tabular}


2-Column $\{2\} \quad$ represents subsystem 2. (Energy Transformation Column) MV / HV transformers with four (04) transformers:

\begin{tabular}{|c|c|c|c|c|}
\hline & 1 & 2 & 3 & 4 \\
\hline Gi \% & 100 & 97 & 99 & $\mathbf{8 0}$ \\
\hline $\mathbf{P i} \%$ & 89.9 & 96 & 69.7 & $\mathbf{8 9 . 7}$ \\
\hline Ci \% & $\mathbf{1 4 0}$ & $\mathbf{2 1 5 . 6}$ & $\mathbf{3 0}$ & $\mathbf{7 4}$ \\
\hline
\end{tabular}

3-Column $\{3\}$ represents subsystem 3 (HT Transport Line Column) which has five (05) lines.

\begin{tabular}{|c|c|c|c|c|c|}
\hline & $\mathbf{1}$ & $\mathbf{2}$ & $\mathbf{3}$ & $\mathbf{4}$ & $\mathbf{5}$ \\
\hline Gi \% & 100 & 100 & 98 & 100 & $\mathbf{1 2 0}$ \\
\hline Pi \% & 78 & 79.8 & 98 & 79.8 & $\mathbf{8 9 . 8}$ \\
\hline Ci \% & $\mathbf{2 1}$ & $\mathbf{3 2}$ & $\mathbf{5 0}$ & $\mathbf{2 1}$ & $\mathbf{8 0 . 1}$ \\
\hline
\end{tabular}

4-Column $\{4\}$ represents Subsystem 4 (Transformer Column HT / MT) which has three (04) transformers.

\begin{tabular}{|c|c|c|c|c|}
\hline & $\mathbf{1}$ & $\mathbf{2}$ & $\mathbf{3}$ & $\mathbf{4}$ \\
\hline Gi \% & 96 & 98 & 100 & $\mathbf{1 0 0}$ \\
\hline Pi \% & 97 & 79.7 & 98 & $\mathbf{8 9 . 5}$ \\
\hline Ci \% & $\mathbf{3 9}$ & $\mathbf{7 5}$ & $\mathbf{1 2 0}$ & $\mathbf{2 5}$ \\
\hline
\end{tabular}

5-Column $\{5\}$ represents subsystem 5 (MT Line Column) which has seven (07) lines.

The demand of the customers HT and MT which represents the $20 \%$ in HT and $80 \%$ in MT for the current year is estimated at a power of $800 \mathrm{Mw}$ on the electrical network. This request is estimated on an annual basis of $8760 \mathrm{~h}$. The demand is $100 \%$ for an annual peak of halfyearly value which is reduced to $75 \%$ during one quarter so the reduction is followed by 50 and $25 \%$ during the other two remaining quarters. Table 1 illustrates this cumulative demand.

\begin{tabular}{|c|c|c|c|c|c|c|c|}
\hline & $\mathbf{1}$ & $\mathbf{2}$ & $\mathbf{3}$ & $\mathbf{4}$ & $\mathbf{5}$ & $\mathbf{6}$ & $\mathbf{7}$ \\
\hline Gi \% & 98 & 100 & 95 & 90 & 100 & 96 & $\mathbf{8 5}$ \\
\hline Pi \% & 95 & 89.5 & 79.5 & 65 & 85 & 89.8 & $\mathbf{7 9 . 9}$ \\
\hline Ci \% & $\mathbf{4 1 . 5}$ & $\mathbf{2 1 0}$ & $\mathbf{1 0}$ & $\mathbf{6 1}$ & $\mathbf{8 1}$ & $\mathbf{9 9}$ & $\mathbf{1 1 0}$ \\
\hline
\end{tabular}

Table 1 Characteristics of Predisposed Elements

\begin{tabular}{|c|c|c|c|c|}
\hline Level of request (\%) & 100 & 75 & 50 & 25 \\
\hline Duration (h) & 4380 & 1095 & 1095 & 1095 \\
\hline Reliability (\%) & 50 & 12.5 & 12.5 & 12.5 \\
\hline
\end{tabular}

For the primal problem, the results obtained by the ant colonies for the reliability thresholds, $0.85,0.97$ and 0.99 . It can be seen that by increasing reliability, the cost increases. So, to have better reliability you have to invest more. For a very important reliability level of 0.99 , the cost is important 11.4919. While for a reliability level of 0.97 , the cost is halved 5.5649. Since our goal is to get good reliability at a lower cost, the best configuration is the reliability constraint of 0.97 (Table 2 ).

Table 2 Optimal solutions obtained by ant colony algorithm primal problem

\begin{tabular}{|c|c|}
\hline Contraint of the reliability $\mathrm{R}_{0}$ & \multicolumn{1}{|c|}{99} \\
\hline Best configurations & $\begin{array}{l}\text { Sous Système } 1: 3(3)- \\
1(4) \\
\text { Sous Système 2 : 1(1)- } \\
\text { Sous Système 3 : 2(1)- } \\
1(3)-2(4) \\
\text { Sous Système 4: 4(4) } \\
\text { Sous Système 5: 7(3) }\end{array}$ \\
\hline Reliability calculated R & $\begin{array}{c}\mid c \\
0.97358\end{array}$ \\
\hline Cost of investment in \% (Mln & 5.5649 \\
\hline DA) & 8 \\
\hline Ant & 2 \\
\hline
\end{tabular}

For the dual problem we varied the cost for the different values $10 \%, 15 \%$ and $20 \%$. We can see that reliability has increased, but the cost has also increased. For the dual problem, you have to invest more to have good reliability (Table 3).

Table 3 Optimal solutions obtained by ant colony algorithm dual problem

\begin{tabular}{|c|c|}
\hline $\begin{array}{c}\text { Contraint of the } \\
\text { cost of } \\
\text { investment in } \\
\% \text { (Mln DA) }\end{array}$ & \\
\hline Best & Subsystem1 :1(1)-1(2)-1(3)-1(4) \\
configurations & $\begin{array}{l}\text { Subsystem2:1(1)-1(2)-1(3)-1(4) } \\
\text { Subsystem3 :2(1)-1(2)-1(4)-1(5) } \\
\text { Subsystem4 :1(1)-1(2)-1(3)-1(4) } \\
\text { Subsystem5:1(1)-1(2)-1(3)-1(4)- } \\
\\
\text { 1(5)-1(6)-1(7) }\end{array}$ \\
\hline
\end{tabular}




\begin{tabular}{|c|c|}
\hline $\begin{array}{c}\text { Reliability } \\
\text { calculated R }\end{array}$ & 0.995067 \\
\hline $\begin{array}{c}\text { Cost of } \\
\text { investment in } \\
\% \text { (Mln DA) }\end{array}$ & 16.837 \\
\hline Cycle & 4 \\
\hline Ant & 4 \\
\hline
\end{tabular}

For the trial problem, we varied the reliability for the different values $85 \%, 97 \%$ and $99 \%$ and the cost for the different values $10 \%, 15 \%$ and $20 \%$. It is found that reliability has increased, but the cost has also increased by linear proportionality. The second configuration is the best because you get good reliability with a reduced cost (Table 4).

Table 4 Optimal solutions obtained by ant colony algorithm trial problem

\begin{tabular}{|c|c|}
\hline $\begin{array}{c}\text { Constraint of } \\
\text { Reliability } R_{0} \\
\text { and Cost C }\end{array}$ & $\begin{array}{l}97 \\
15\end{array}$ \\
\hline $\begin{array}{c}\text { Best } \\
\text { configurations }\end{array}$ & $\begin{array}{l}\text { Sous Système } 1: 1(1)-1(2)- \\
1(3)-1(4) \\
\text { Sous Système } 2: 1(1)-1(2)- \\
1(3)-1(4) \\
\text { Sous Système } 3: 1(1)-1(2)- \\
1(3)-1(4)-1(5) \\
\text { Sous Système } 4: 1(1)-1(2)- \\
1(3)-1(4) \\
\text { Sous Système } 5: 2(1)-2(3)- \\
1(4)-1(5)-1(6)\end{array}$ \\
\hline $\begin{array}{l}\text { Reliability } \\
\text { calculated R }\end{array}$ & 0.99578 \\
\hline $\begin{array}{c}\text { Cost } \\
(\mathrm{M} \ln \mathrm{DA}) \\
\end{array}$ & 16.427 \\
\hline Cycle & 192 \\
\hline Ant & 3 \\
\hline
\end{tabular}

\section{CONCLUSION}

In this article, we have optimized the electrical network in presenting a problem concerning the taking into account of three types of problems to the investors to make the choice according to their planned objectives:

* The first formulation allows us to have a low-cost design from the point of view of production and structure while guaranteeing an acceptable level of reliability this type is Primal.

* The second wording gives investors the opportunity to achieve their desired level of security while respecting the turnover to be allocated to the Dual type project.

* The third formulation allows us to have a compromise between the type Primal and Dual it is a type Min-Max or / and Max-Min.
These three formulations act in permutation between three nonlinear objective functions with their nonlinear constraints.

In this context, we have developed a specific Java platform program based on the ACO approach that optimizes objectives planned under "reliability - cost / performance" constraints.

The first formulation allows us to have an optimal system investment cost (component and energy production) in a range of 5.5-11.4\% compared to the level of reliability required by the customer $85-99 \%$. These results show a proportionality between an investment and a high security of the optimal system to design.

The second formulation allows us to have optimal designs with high reliability (system components and power) in a range of $98.7-99.5 \%$ corresponding to investments of $9.7-16.8 \%$.

The third formulation allows us to have optimal designs to compromise between a high reliability / a minimum cost of investment on (system components and power) it is a type of problem Max-Min this last formulation belonging to the domain multi-objective. The simulation results led us to make the compromise between these two decision variables. The optimal configuration is $96.6-99.5 \%$ and $7.93-16.4 \%$ of compromise between reliability / cost respecting the budget guarantee to allocate thus a safety threshold of: $85-99 \%$ and $10-20 \%$.

\section{ACKNOWLEDGMENTS}

My thanks for professor Abdelhalim Benmansour, for having encouraged, reviewed, commented and corrected the article.

\section{REFERENCES}

[1] EL-NEWEIHI - PROSCHAN: Degradable systems: A survey of multi-states system theory. Common. Statist. Theor. math., 13(4), 1984.

[2] REEVES, C. R. (Ed.): Modern heuristic techniques for combinatorial problems, Blackwell Scientific Publications, Oxford, 1993.

[3] MEZIANE, R. - MASSIM, Y. - ZEBLAH, A. GHORAF, A. - RAHLI, M.: Reliability Optimization Using Ant Colony Under Cost and Performance Constraintes, Power System Research Journal ESRJ, 2005, Elsevier Publisher, Vol. No.76, pp-1-8, 2005.

[4] ZEBLAH, A. - GHORAF, A. - HADJERI, S. HAMDAOUI, H.: Optimization for Series-Parallel Continuous Power Systems with Buffers Uder Reliability Constraints Using Ant Colony Accepted paper in international Journal of Industrial and Management Optimization, Vol. No. 2, Number 4, pp467-479 (JIMO) 2006.

[5] MASSIM, Y. - ZEBLAH, A. - MEZIANE, R. RAHLI, M.: Ant Colony Optimization For MultiState Series-parallel System Expansion-Sheduling, Electrical Engineering Journal, Springer Verlags, under press, 2005.

[6] MASSIM, Y. - ZEBLAH, A. - GHORAF, A. MEZIANE, R.: Reliability Evaluation Of Multi-State 
Series-Parallel Power System Under Multi- States Constraints, Electrical Engineering Journal, Springer Verlags, Vol. No. 87, pp-327-336, 2005.

[7] BULLNHEIMER, B. - HARTL, R. F. - STRAUSS, C.: A new rank-based version of the ant system: a computational study, Central European Journal of Operations Research 7 (1) (1999), 25-38.

[8] HAO, J. K. - GALINIER, P. - HABIB, M.: Méta heuristiques pour l'optimisation combinatoire et l'affectation sous contraintes, Revue d'Intelligence Artificielle, Vol. No. 1999.

[9] DREO, J. - PETROWSKI, A. - SIARRY, P. TAILLARD, E.: Méta- heuristiques pour l'optimisation difficile, Eyrolls, 2003.

[10] VOSS, S. - MARTELLO, S. - OSMAN, I. H. ROUCAIROL, C. (Eds.): Meta-Heuristics: Advances and Trends in Local Search Paradigms for Optimization, Kluwer, Boston, 1999.

[11] DORIGO, M.: Optimization, learning and natural algorithms, Ph.D. Thesis, Politecnico di Milano, Milano, 1992.

[12] MANIEZZO, V. - DORIGO, M. - COLORNI, A.: The ant system: Optimization by a colony of cooperating agents. IEEE Transactions on Systems, Man, and Cybernetics-Part B, 26(1) :29-41, 1996.

[13] BLUM, C. - SAMPELS, M.: Ant colony optimization for FOP shop scheduling: a case study on different pheromone representations, in Proceedings of the 2002 congress on Evolutionary Computation, Honolulu, USA.

[14] DEN BESTEN, M. - STÜTZLE, T. - DORIGO, M.: Ant colony optimization for the total weighted tardiness problem, Parallel Problem Solving from Nature: 6th international conference, September 2000. Springer Verlag.

[15] CORDON, O. - FERNANDEZ DE VIANA, I. HERRERA F. - MORENO, L.: A new ACO model integrating evolutionary computation concepts: the best-worst ant system, in Proceedings of ANTS2000 -from ant colonies to artificial ants, Universitè Libre de Bruxelles.
[16] DORIGO, M. - DI CARO, G. (1999): The Ant Colony Optimization Meta-Heuristic. Numurical analysis Mac Grawhil Topic Computer science serie.

[17] DORIGO, M. - DI CARO, G. - GAMBARDELLA, L. M. (1999): Ant Algorithms for Discrete Optimization. Artificial Life, 5(2):137-172.

[18] DORIGO, M - GAMBARDELLA, L. M.: Ant colony system: a cooperative learning approach to the traveling salesman problem, IEEE Transaction on Evolutionary Computation 1 (1997), 53-66.

[19] BOURI, S. - ZEBLAH, A. - GHORAF, S. HADJERI, S. - HAMDAOUI, H.: Ant Colony Optimization to Shunt Capacitor Allocation in Radial Distribution Systems Acta and Electronica et informatic journal Schekoslovacia No. 4, Vol. 5; 2005.

Received November 24, 2018, accepted January 11, 2019

\section{BIOGRAPHIES}

Bouri Sihem was born in Ain Témouchent (Algeria), on August 4, 1976. She graduated the Faculty of Technology, Sidi Bel Abess (Algeria), in 1999. She received the $\mathrm{PhD}$ degree in electrical engineering from the the Faculty of Technology, Sidi Bel Abess (Algeria), in 2008. She is Professor at the Faculty of Technology, in Tlemcen (Algeria). Her research interests concern: power systems, reliability, Universal moment generating Function (UMGF).

Abdelhalim Benmansour was born on January 2, 1957 in Tlemcen (Algeria). He graduated from the University of Sciences and Technology of Algiers in Physics in 1979 and from the National School of Electrical Engineers (ENSIEG) of the National Polytechnic Institute (INPG) of Grenoble (France) in electrical engineering in 1982. He obtained his energetic magister in 1992 and his $\mathrm{PhD}$ in materials science in 2004 at the University of Tlemcen (Algeria). He is professor at the faculty of technology and director of the research unit on materials and renewable energies (URMER) at the University of Tlemcen (Algeria). His research interests include: photovoltaic cells, materials, renewable energy and water treatment. 